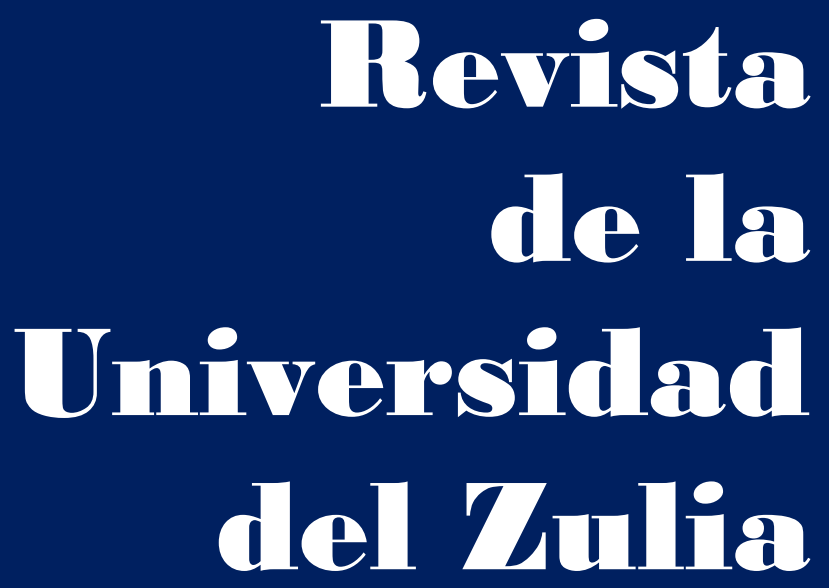

Fundada en 1947

por el Dr. Jesús Enrique Lossada

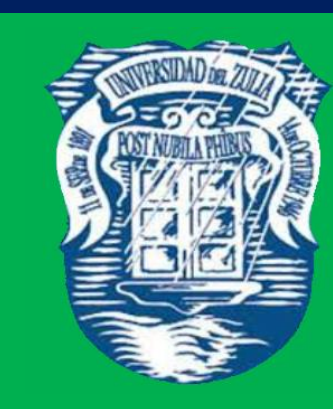

Ciencias del

Agrad,

Ingemiería

y Tecinología

\section{Aกัต 13 No $\mathbf{3 6}$} Enero - Abril 2022

Tercera Épaca

Maracailbo-Venezuela 
REVISTA DE LA UNIVERSIDAD DEL ZULIA. 3ㅜépoca. Año 13 N $^{\circ}$ 36, 2022

Édixon Ochoa/// La territorialidad y el principio del Uti Possidetis Iuris Itapossideatis, 3-6

DOI: http://dx.doi.org/10.46925//rdluz.36.01

\title{
La territorialidad y el principio del Uti Possidetis Iuris Itapossideatis
}

\author{
Édixon Ochoa *
}

RESUMEN

En la presente investigación, fraguada a modo de revisión histórica, jurídica y editorial, se escudriña nuevamente el principio jurídico del uti possidetis iuris itapossideatis que, no obstante, su clásica vinculación con los contextos de demarcación, definición y esclarecimiento de las líneas divisorias internacionales, constituye el fundamento para el abordaje de varias situaciones relacionadas con el concepto de la territorialidad desde una óptica transdisciplinaria.

PALABRAS CLAVE: Frontera; Derecho territorial; instrumento internacional; Derecho de los Estados.

\section{Territoriality and the principle of uti possidetis iuris itapossideatis}

ABSTRACT

In the present investigation, forged as a historical, legal and editorial review, the legal principle of uti possidetis iuris itapossideatis is scrutinized again, which, nevertheless, its classic link with the contexts of demarcation, definition and clarification of international dividing lines, constitutes the foundation for addressing various situations related to the concept of territoriality from a transdisciplinary perspective.

KEYWORDS: Boundaries; Territorial rights; International instruments; Rights of states

*Individuo de Número de la Academia de Historia del estado Zulia (Sillón XXV). Presidente del Capítulo Regional del Zulia y Vocal de la Junta Directiva Nacional del Instituto de Estudios Fronterizos de Venezuela (IDEFV). ORCID: https://orcid.org/0000-0002-3694-0550. E-mail: edixon.ochoa2000@gmail.com 
REVISTA DE LA UNIVERSIDAD DEL ZULIA. 3ㅜépoca. Año 13 N $^{\circ}$ 36, 2022 Édixon Ochoa /// La territorialidad y el principio del Uti Possidetis Iuris Itapossideatis, 3-6 DOI: http://dx.doi.org/10.46925//rdluz.36.01

Un territorio es conceptuado como la apropiación del espacio con fines políticos, gestionado internacionalmente como consecuencia del devenir histórico (Spíndola, 2016). La significación sociocultural de dicho territorio con fines identitarios es lo que se denomina territorialidad, concepto éste que puede abordarse desde miradas históricas, geográficas, sociológicas, jurídicas y hasta literarias.

En el marco de esta mirada transdisciplinaria, se plantea a continuación la revisión de un principio jurídico fundamental para el concepto de territorialidad, allende el enfoque desde el cual pueda ser tratado. Se trata del uti possidetis iuris itapossideatis (como poseísteis, así seguiréis poseyendo), cuyo más lejano antecedente se encuentra en el Tratado de Alianza y Federación entre Cundinamarca y Venezuela, suscrito el 28 de mayo de 1811 en Santa Fe de Bogotá por Jorge Tadeo Lozano de Peralta, Jefe del Poder Electoral Constituyente de Cundinamarca, y el Pbro. Dr. José Cortés de Madariaga, Representante de la Suprema Junta de Caracas (Ojer, 1982). Éste fue el primer instrumento legal bilateral en invocar dicho principio, pues al referirse a la cuestión limítrofe, menciona:

La demarcación y límites de los dos Estados se acordarán por un tratado separado, tirándose la línea divisoria de los dos Estados por la parte que parezca más oportuna, proporcionándose una recíproca indemnización de lo que mutuamente cedan, y esta división se hará por geógrafos nombrados por ambas partes (Perazzo, 1965).

Más adelante, en 182l, luego de enviar ministros plenipotenciarios a Perú, Argentina y México con el propósito de delimitar, federar e integrar a las nuevas repúblicas, Simón Bolívar expresa (Echeverría, 2004):

Las partes se garantiza mutuamente la integridad de sus respectivos territorios en el mismo pie en que se hallaban antes de la presente guerra debiendo respetarse los límites que tenía en aquel tiempo cada Capitanía General o Virreinato que ha reasumido en el día, el ejercicio de su soberanía.

Durante el periodo colonial, España creó diversos tipos de circunscripciones territoriales: comerciales (intendencias y consulados), judiciales (audiencias o presidencias), eclesiásticas (misiones, diócesis y arquidiócesis), y jurídico-militares (virreinatos y capitanías 
REVISTA DE LA UNIVERSIDAD DEL ZULIA. 3ㅜépoca. Año 13 N $^{\circ}$ 36, 2022 Édixon Ochoa /// La territorialidad y el principio del Uti Possidetis Iuris Itapossideatis, 3-6 DOI: http://dx.doi.org/10.46925//rdluz.36.01

generales). Éstas últimas eran las más precisas, por lo cual Bolívar las escoge, no hablando de herencia hispana, sino de reconocimiento mutuo de los territorios poseídos por tales entidades, de las cuales emergían las repúblicas. A esto agrega una fecha límite: antes y después de 1810, que selecciona especialmente para Suramérica, pues fue en este año cuando la mayoría de las colonias hispanoamericanas inició su transformación política (Echeverría, 2004).

Una vez culminada la emancipación de Hispanoamérica en 1824, las incipientes repúblicas emprendieron la búsqueda de un principio jurídico propio, fundamentado en la tradición y la aceptación colectiva, que constituyera el punto de partida para la delimitación de sus territorios. Para ello, Bolívar elige una regla jurídica del derecho romano. Según éste, los pretores fallaban provisionalmente el derecho de ocupación de un solar u objeto a favor del ocupante: mientras se demuestra lo contrario, es de quien lo tiene. Era un uti possidetis facti (como lo poseísteis de hecho). Bolívar reformula la regla manifestando su contraparte, es decir, el uti possidetis iuris (como lo poseísteis de derecho) (Echeverría, 2004).

El nuevo principio jurídico fue acogido por las repúblicas hispanoamericanas, hallándose plenamente asentado para 1830, año desde el cual estuvo consagrado, por cierto, en todas las constituciones de Venezuela promulgadas hasta la presente fecha Años después, en 1845, España reconoció oficialmente la independencia de sus antiguas colonias y sus fundamentes jurídicoterritoriales. En 1847, el uti possidetis iuris itapossideatis fue aprobado y ratificado en el Congreso Hispanoamericano de Lima (Echeverría, 2004). Su aplicación se vislumbró sencilla: para determinar que un territorio pertenecía a determinada nación hispanoamericana, bastaría con demostrar que dicho territorio pertenecía al país en cuestión para 1810.

Sin embargo, en 1883, a propósito del centenario del natalicio de Simón Bolívar, numerosos dignatarios extranjeros se reunieron en Caracas. El entonces presidente Antonio Guzmán Blanco reunió a los latinoamericanos y les presentó un protocolo confidencial, a consideración de sus gobiernos. En él se instaba a reconocer, entre otros aspectos, el uti possidetis iuris itapossideatis como base del derecho internacional de América, que se consagraría en un congreso continental convocado a tal efecto. Las respuestas fueron excusas, ambigüedades y negaciones, siendo estas últimas las de Argentina y Chile (Consalvi, 2011). 


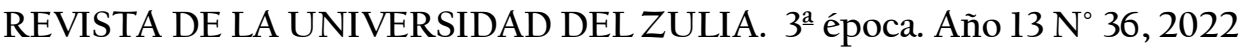
Édixon Ochoa /// La territorialidad y el principio del Uti Possidetis Iuris Itapossideatis, 3-6 DOI: http://dx.doi.org/10.46925//rdluz.36.01

Así fue como surgió un principio jurídico novedoso, aunque de raíces pretéritas, esencial para la tranquilidad de las repúblicas hispanoamericanas, en pro de solucionar sus problemas internos territoriales como también para contrarrestar las pretensiones geófagas de las potencias europeas de entonces. Una norma jurídica que ha sido aplicada, incluso, en el resto del orbe por no pocos países, entre ellos, las propias potencias europeas en sus antiguas posesiones coloniales, al momento de dirimir sus eventuales litigios fronterizos. En suma, el uti possidetis iuris itapossideatis trascendió y perduró hasta la actualidad como doctrina del derecho público moderno.

\section{Referencias}

Echeverría, J. (2004). Los límites colombo-venezolanos en la Guajira (2ª edición). Maracaibo: EDILUZ. Consalvi, S. (2011). "La política exterior de Venezuela durante la época de Antonio Guzmán Blanco" en: Los tiempos envolventes del guzmancismo. Caracas: Fundación John Boulton, UCAB.

Ojer, P. (1982). La década fundamental en la controversia de límites entre Venezuela y Colombia (1881-1891). Maracaibo: Biblioteca CORPOZULIA.

Perazzo, N. (1965). Josef Cortes Madariaga (Padre Madariaga). Caracas: Colección Libros Revista Bohemia.

Spíndola, O. (2016). "Espacio, territorio y territorialidad: una aproximación teórica a la frontera”. Revista Mexicana de Ciencias Políticas y Sociales. Ciudad de México: Universidad Nacional Autónoma de México, Nueva Época, Año LXI, No 228, septiembre-diciembre de 2016, p. 27-56. 